\title{
Anti-photoaging effect of fermented rice bran extract on UV-induced normal skin fibroblasts
}

\author{
Young-Kwon Seo $\cdot$ Su-Hyun Jung $\cdot$ Kye-Yong Song $•$ \\ Jung-Keug Park $\cdot$ Chang-Seo Park
}

Received: 12 November 2009/Revised: 11 March 2010/Accepted: 15 March 2010/Published online: 1 April 2010

(C) The Author(s) 2010. This article is published with open access at Springerlink.com

\begin{abstract}
Rice bran contains various polyphenolic compounds with anti-oxidative activities, and it has long been known to inhibit melanogenesis. Cofermentation of rice bran with Lactobacillus rhamnosus and Saccharomyces cerevisiae significantly reduced the melanin synthesis of the resulting extract to B16F1 melanoma cells. However, anti-aging and anti-inflammatory effects of these fermented rice bran extracts (FRBEs) were not investigated. The objective of this work was to investigate the ability of FRBE to protect fibroblast cultures against ultraviolet $\mathrm{B}$ (UV-B)-induced damage in vitro. To study the effect of FRBE on collagen synthesis, human fibroblasts were treated with $0.1,0.5$, or $1 \%$ of FRBE or $25 \mu \mathrm{M}$ of As-2p over 3 days. The morphological change of fibroblasts, secretion of IL- $1 \alpha$, and pro-MMP- 1 levels were evaluated. The rate of cell growth was reduced upon exposure of fibroblasts to UV-B radiation $\left(30 \mathrm{~mJ} / \mathrm{cm}^{2}\right)$ and did not recover after FRBE treatment. FRBE did not induce morphological changes and necrosis in a dose-dependent manner.
\end{abstract}

Y.-K. Seo

Dongguk University Research Institute of Biotechnology,

Dongguk University, 3-26, Choong Gu, Seoul 100-715, Korea

S.-H. Jung · C.-S. Park ( $\square)$

Department of Chemical and Biochemical Engineering,

Dongguk University, 3-26, Choong Gu,

Seoul 100-715, Korea

e-mail: dgucsp@dongguk.edu

K.-Y. Song

Department of Pathology, Chung-Ang University,

221, Dongjak Gu, Seoul 156-756, Korea

J.-K. Park

Department of Medical Biotechnology, Dongguk University,

3-26, Choong Gu, Seoul 100-715, Korea
Immunohistochemistry confirmed increased collagen synthesis in a dose-dependent manner after UV-irradiated fibroblasts were treated with FRBE. FRBE treatment reduced the UV-B-induced release of IL- $1 \alpha$ to levels found in non-irradiated controls. In fibroblasts subjected only to UV-B irradiation, the level of pro-MMP-1 increased approximately fourfold compared to non-irradiated cells. However, treatment with FRBE decreased the level of proMMP-1 to a level similar to that of As-2p treated cells; this result was confirmed by western blot analysis. This work indicates that FRBE can increase the synthesis of type I collagen, decrease the expression of MMP-1, and inhibit the production of IL- $1 \alpha$ in UV-B irradiated human fibroblasts.

Keywords Fermented rice bran extract · Anti-aging · Anti-inflammation · Collagen · Fibroblast

\section{Introduction}

Skin photoaged by UV radiation displays multiple histological features that reflect chronic skin inflammation and connective tissue damage [1]. The dermal damage induced by UV is principally manifested as destruction of the dermal extracellular matrix (ECM), which is composed primarily of type I collagen, elastin, proteoglycans, and fibronectin [2]. These clinical and structural changes in aged skin are due mainly to the degradation of collagen and the accumulation of abnormal elastin in the dermal ECM upon UV exposure. An increased number of immune cells also contribute to the aging process. As a result of UV exposure, collagen-degrading matrix metalloproteinase (MMP)-1, also known as collagenase, is upregulated in skin and serves as the primary matrix metalloproteinase. 
Therefore, excessive degradation of collagen and the matrix by UV-induced MMPs is a characteristic feature of severely photodamaged skin and contributes substantially to dermal damage.

Treatment of the skin with products containing plantderived antioxidant ingredients has proven useful for the prevention of UV-mediated cutaneous damage [3]. Various plant-derived flavonoid extracts from licorice, tart cherries, siderites, and leguminosae have been shown to possess antioxidant activity; they act as scavengers of various oxidizing species (e.g. superoxide anion, hydroxyl radical, peroxyl radical) [4]. They may also act as quenchers of singlet oxygen. Berberine, a plant ingredient with antiinflammatory and anti-oxidative effects, was recently demonstrated to inhibit MMP-1, MMP-8, and IL-6 expression and to increase type I procollagen expression in skin cells in a dose-dependent manner $[5,6]$. Black tea constituents (theaflavin and its derivatives) possess strong anti-inflammatory activity in vivo, possibly due to the inhibition of arachidonic acid via lipoxygenase and the COX pathways [7]. In another study, ferulic acid, a phenolic compound with strong membrane antioxidant and anti-inflammatory activity [8, 9], solely reduced UVinduced erythema in humans [10].

Numerous features that promote health have been observed in fermented rice bran through previous research. For example, anti-stress and anti-fatigue effects were indicated by the inhibition of major weight changes in the adrenal, thymus, spleen, and thyroid, and it was shown to prolong swimming time of mice [11]. Moreover, it is regarded as highly nutritional due to significant amounts of lipid, protein, vitamin $\mathrm{B}$, and essential amino acids [12, 13]. Other various compounds (e.g. phenolic acid, ferulic acid, vanillic acid, protocatechuic acid, $\gamma$-oryzanol, phytic acid, inositol) were also found [14]. Phenolic acids and anthocyanins typically act as antioxidants and antiinflammatory agents $[15,16]$. Specifically, anthocyanins in rice bran extract play an important role as dietary antioxidants in the prevention of lipid peroxidation of cell membranes induced by active oxygen radicals in living systems $[17,18]$. The predominant anthocyanins in rice bran were identified as cyanidin $3-O-\beta$-D-glucoside and peonidin 3-O- $\beta$-D-glucoside [19-21]. The cyanidin and malvidin isolated from pigmented rice bran demonstrated anticarcinogenic and antimutagenic activity in the inhibition of leukemia cell growth [22, 23]. In addition, a recent report showed that oral ingestion of rice wine and its topical application relieved epidermal barrier disruption caused by UV [24]. However, scientific evidence for the various in vitro effects of fermented rice bran on skin fibroblasts is lacking.

The purpose of this study was to investigate whether fermented rice bran extract (FRBE) was able to ameliorate
UV-B-induced damages in fibroblast culture by analyzing cell viability and morphology (as markers of cell toxicity), production of interleukin (IL)- $1 \alpha$ (as a marker of inflammatory reaction), expression of pro-MMP-1 and MMP-1, and collagen synthesis (as markers of anti-aging effects).

\section{Materials and methods}

\section{Preparation of FRBE}

Fermented rice bran was prepared according to the following methods. Rice bran ( $408 \mathrm{~g}$ ) was saccharified with $72 \mathrm{~g}$ of koji (Aspergillus oryzae) enzymes, including $0.39 \mathrm{~mL}$ of $\alpha$-amylase and $0.39 \mathrm{~mL}$ of glucoamylase, at $60{ }^{\circ} \mathrm{C}$ for $150 \mathrm{~min}$. Saccharomyces cerevisiae $\left(1 \times 10^{5}\right.$ $\mathrm{cfu} / \mathrm{mL})$ and Lactobacillus rhamnosus $\left(1 \times 10^{5} \mathrm{cfu} / \mathrm{mL}\right)$ were used to stimulate fermentation at $15^{\circ} \mathrm{C}$ for 15 days. After centrifugation $(4,300 \mathrm{rpm}, 30 \mathrm{~min})$ and filtration fermented rice bran was treated with activated carbons and enriched fivefold by vacuum evaporation. The final batch of FRBE was prepared by the water extraction method [25].

Primary culture of human skin dermal fibroblasts

Primary cultured human skin fibroblasts were aseptically isolated from a circumcised neonatal foreskin at ChungAng University Hospital (Yong San, Korea). The obtained foreskin was immersed at $4{ }^{\circ} \mathrm{C}$ in Dulbecco's modified Eagle medium (DMEM) containing antibiotic-antimycotic agent $(100 \mathrm{unit} / \mathrm{mL}$ penicillin $\mathrm{G}$ sodium, $100 \mathrm{unit} / \mathrm{mL}$ streptomycin sulfate, $0.25 \mu \mathrm{g} / \mathrm{mL}$ amphotericine B; WellGen, Korea). Next, the foreskin was immersed in DMEM containing 1.4 units/mL protease (Dispase, Sigma Chemical Company, St. Louis, MO, USA) for $16 \mathrm{~h}$ at $4{ }^{\circ} \mathrm{C}$. Epidermal layers were mechanically stripped, and the normal fibroblasts were isolated from the dermis using 362 unit/mL type I collagenase (type IA, Sigma Chemical Company, St. Louis, MO, USA) for $90 \mathrm{~min}$ at $37^{\circ} \mathrm{C}$. Following this enzymatic treatment, DMEM supplemented with $10 \%$ fetal bovine serum (FBS) was added to the cellular suspension, followed by centrifugation for $5 \mathrm{~min}$ at $1,000 \mathrm{rpm}$ to recover fibroblasts from the culture medium. Fibroblasts were routinely cultured in DMEM and supplemented with $10 \% \mathrm{FBS}$ at $37{ }^{\circ} \mathrm{C}$ in a $5 \% \mathrm{CO}_{2}$ incubator.

Cell culture and FRBE or ascorbic acid 2-phosphate treatment

Fibroblasts (at the fifth passage) were seeded at a density of $1 \times 10^{5}$ cells/well in a six-well plate, washed once with PBS, and UV-B-irradiated $\left(30 \mathrm{~mJ} / \mathrm{cm}^{2}\right) 24 \mathrm{~h}$ later. After 
irradiation, cells were cultured in DMEM/10\% FBS containing $0.1,0.5$, or $1 \%(\mathrm{v} / \mathrm{v})$ FRBE or $25 \mu \mathrm{M}$ of ascorbic acid 2-phosphate (As-2P) for 3 days. Generally, anti-aging effect tests have used As- $2 \mathrm{P}$ as a comparison material in many other anti-aging effect analysis. Samples were divided into six groups: non-UV-B irradiation (negative control), UV-B irradiation (positive control), As-2P added after UV-B irradiation, 0.1\% (v/v) FRBE added after UV-B irradiation, $0.5 \%(\mathrm{v} / \mathrm{v})$ FRBE added after UV-B irradiation, and $1 \%(\mathrm{v} / \mathrm{v})$ FRBE added after UV-B irradiation.

\section{Cell proliferation assay}

Cell proliferation was measured using a 3-[4,5-dimethylthiazol-2-yl]-2,5-diphenyl tetrazolium bromide (MTT, Sigma) assay. Briefly, serum-free DMEM was added to each well and supplemented with MTT $(0.33 \mu \mathrm{g} / \mathrm{mL})$. The plates were incubated in the dark at $37{ }^{\circ} \mathrm{C}$ in an atmosphere containing $5 \% \mathrm{CO}_{2}$ for $2 \mathrm{~h}$ followed by aspiration of the supernatant. Isopropyl alcohol $(1 \mathrm{~mL})$ containing $0.04 \mathrm{~N}$ $\mathrm{HCl}$ was added, and the dish was slowly shaken for $15 \mathrm{~min}$. The absorption was measured at $540 \mathrm{~nm}$.

\section{Immunohistochemical analysis}

Cultured fibroblasts were fixed for $1 \mathrm{~h}$ at $4{ }^{\circ} \mathrm{C}$ using $10 \%$ neutral buffered formalin followed by immunohistochemical staining on the culture dishes. Endogenous peroxidase $\left(0.03 \% \mathrm{H}_{2} \mathrm{O}_{2}\right)$ was used for blocking followed by the nonspecific reaction of bovine serum albumin and non-immune serum with either monoclonal pro-collagen antibody (NeoMarker, Lab Vision Corp, Fremont, CA, USA). The standard immunohistochemical procedure was conducted using either anti-goat or anti-rabbit immunoglobulin according to the Avidin-Biotin Peroxidase Complex (ABC) method.

\section{Western blot analysis}

Cells were lysed in a buffer consisting of $62.5 \mathrm{mM}$ Tris- $\mathrm{HCl}(\mathrm{pH}$ 6.8), 2\% SDS, 5\% $\beta$-mercaptoethanol, $2 \mathrm{mM}$ phenylmethyl-sulfonyl fluoride, protease inhibitors (Complete $^{\mathrm{TM}}$, Roche, Mannheim, Germany), $1 \mathrm{mM}$ $\mathrm{Na}_{3} \mathrm{VO}_{4}, 50 \mathrm{mM} \mathrm{NaF}$, and $10 \mathrm{mM}$ EDTA. Ten micrograms of protein was separated by SDS-polyacrylamide gel electrophoresis and blotted onto polyvinylidene fluoride membranes saturated with $5 \%$ dried milk in Trisbuffered saline containing $0.5 \%$ Tween 20 . A polyclonal, anti-MMP-1 antibody was used as the primary antibody. Blots were incubated with the appropriate primary antibody at a dilution of 1:1,000 followed by further incubation with horseradish peroxidase-conjugated secondary antibody.
Intracellular collagen analysis

Total intracellular soluble collagen was measured using a Sircol $^{\mathrm{TM}}$ Collagen Assay Kit (Bioassay Inc.). Briefly, collagen samples were prepared from fibroblast cultures incubated with various FRBE concentrations. Cultured cells were lysed with $500 \mu \mathrm{l}$ of Proprep solution and sonicated for $5 \mathrm{~min}$. Following preparation, samples were mixed with Sircol Dye reagent. After centrifugation $(10,000 \mathrm{~g}$ for $10 \mathrm{~min})$ the mixtures were dissolved in alkali reagent, and the absorbance was measured at $540 \mathrm{~nm}$.

\section{ELISA assay}

Secreted Interleukin- $1 \alpha$ (IL- $1 \alpha$ ) and pro-MMP-1 were estimated by ELISA assays using human immunoassay kit (BIOSOURCE, LHC0011 for pro-MMP-1 and KAC1191 for human IL-1 $\alpha$ ). The procedure was performed manually, and the absorption was measured at $450 \mathrm{~nm}$.

Statistical analysis

Data were statistically evaluated using the ANOVA test. The difference between the means was considered significant when $P \leq 0.05$.

\section{Results and discussion}

Figure 1 shows that exposure to UV-B irradiation $(30 \mathrm{~mJ} /$ $\mathrm{cm}^{2}$ ) reduced the cellular growth rate of the fibroblasts. However, FRBE treatment did not produce any improvement, since the cell growth in fibroblast cultured with 0.1, 0.5 or $1 \%$ FRBE after UV irradiation was lower than that of non-irradiated and As-2P $(25 \mu \mathrm{M})$ treated cells (Fig. 1).

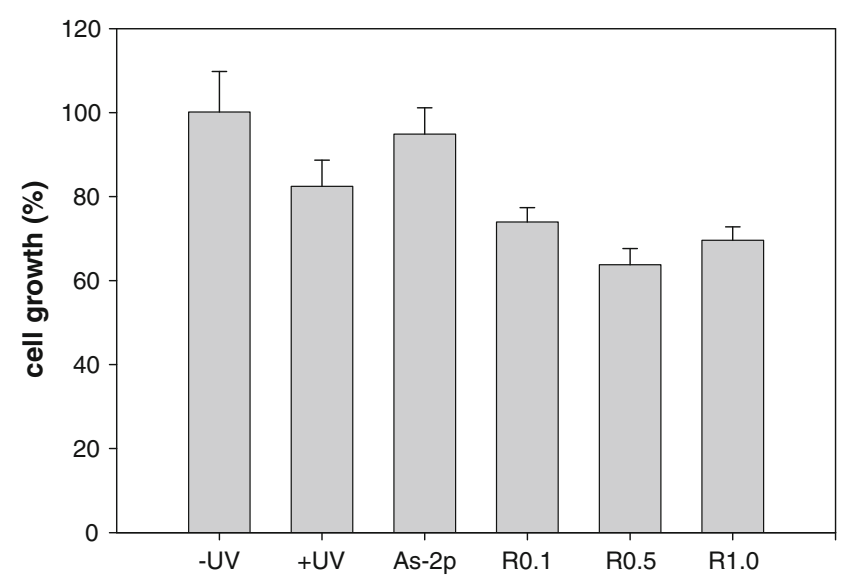

Fig. 1 Effect of fermented rice bran extract (FRBE) on the growth of skin fibroblasts exposed to UV-B radiation at $30 \mathrm{~mJ} / \mathrm{cm}^{2}(n=6)$. Data are expressed as mean \pm SD of six samples $(* P<0.05)$ 
Figure 2 shows the morphology of cultivated fibroblasts 3 days after UV irradiation. In this study, no morphological changes or necrosis were observed after UV irradiation because UV dose was low (Fig. 2b). Also, this study demonstrated that FRBE did not induce morphological changes or necrosis in a dose-dependent manner. Therefore, it was revealed that FRBE does not induce toxicity (Fig. 2c-f).

To study the effect of FRBE on the synthesis of collagen, human fibroblasts were treated with $\operatorname{FRBE}(0.1,0.5$, or $1 \%$ ) or $25 \mu \mathrm{M}$ of As-2p over 3 days. The collagen content was $3.1 \pm 0.02 \mu \mathrm{g}$ in the non-irradiated cells, but collagen was $1.8 \pm 0.1 \mu \mathrm{g}$ in UV-irradiated cells. Further, collagen content was $2.2 \pm 0.3 \mu \mathrm{g}$ in the As-2P-treated cells, $2.0 \pm 0.2 \mu \mathrm{g}$ in the $0.1 \%$ FRBE-treated cells, $2.8 \pm$ $0.15 \mu \mathrm{g}$ in the $0.5 \%$ FRBE-treated cells, and $3.1 \pm 0.4 \mu \mathrm{g}$ in $1.0 \%$ FRBE-treated cells (Fig. 3). As a result, $0.5 \%$ and
$1 \%$ FRBE increased collagen synthesis in a dose-dependent manner at a rate comparable to that of the As-2P-treated cells.

Immunohistochemistry showed that FRBE treatment could impact pro-collagen synthesis in the cell. In response to UV exposure, a reduction in pro-collagen protein was detected by staining the cells (Fig. 4a). However, the procollagen staining analysis showed that FRBE increased collagen synthesis in fibroblasts after UV irradiation, and this increase occurred in 0.5 and 1\% FRBE. These results indicate FRBE treatment could be used to increase collagen expression in human skin fibroblasts (Fig. 4).

To evaluate the effect of FRBE on UV-B induced inflammation, we chose to study the baseline and UV-modulated production of IL- $1 \alpha$ in culture media. The secretion of IL- $1 \alpha$ was $7.5 \pm 0.2 \mathrm{pg} / \mathrm{mL}$ in the non-UV-irradiated cells, but the level of IL- $1 \alpha$ was $11.5 \pm 1.0 \mathrm{pg} / \mathrm{mL}$ in the
Fig. 2 Phase-contrast photography of human skin fibroblasts culture (a No UVirradiation, b UV-irradiation, $\mathbf{c}$ As- $2 p$ treatment after UVirradiation, d $0.1 \%$ FRBE treatment after $\mathrm{UV}$-irradiation, $\mathbf{e}$ $0.5 \%$ FRBE treatment after UVirradiation, $\mathbf{f} 1 \%$ FRBE treatment after UV-irradiation). Original magnification: 100 , scale bar $200 \mu \mathrm{m}$
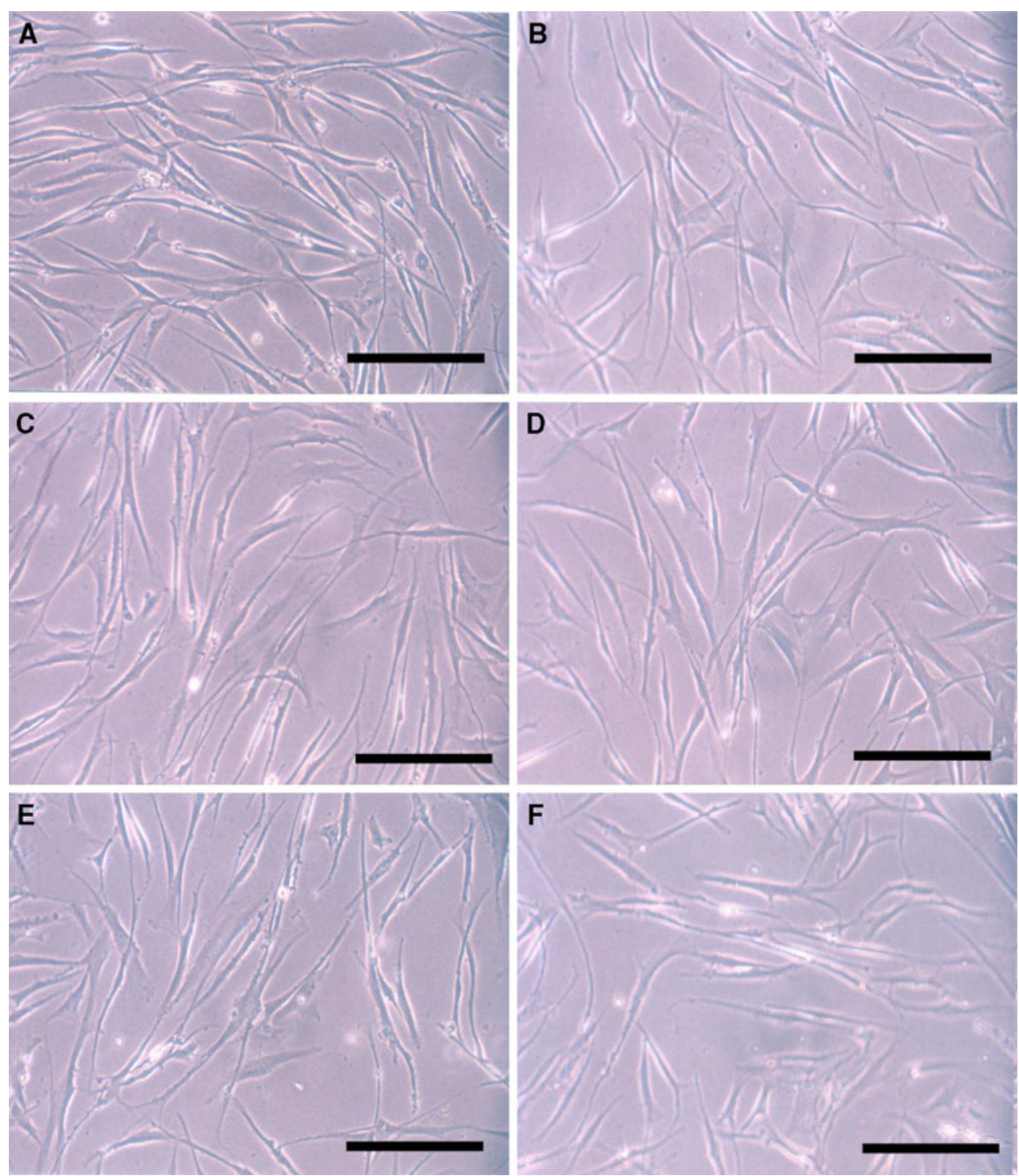


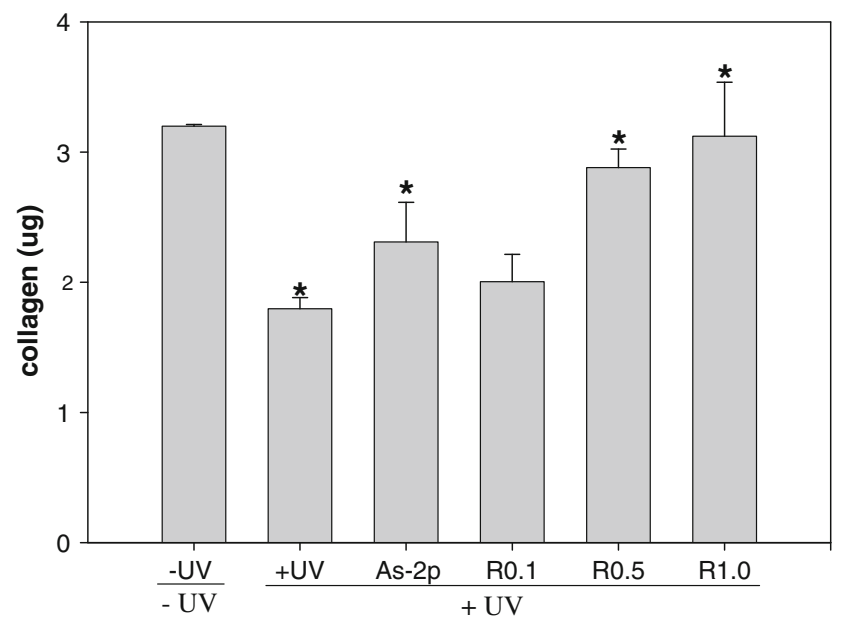

Fig. 3 Effect of FRBE on collagen synthesis in skin fibroblasts exposed to UV-B radiation at $30 \mathrm{~mJ} / \mathrm{cm}^{2}(n=6)$. Data are expressed as mean $\pm \mathrm{SD}$ of six samples $(* P<0.05)$
UV-irradiated cells. The IL- $1 \alpha$ content was $9.8 \pm 0.3 \mathrm{pg} /$ $\mathrm{mL}$ in the As-2P-treated cells, but $8.8 \pm 0.2 \mathrm{pg} / \mathrm{mL}$ in the $0.1 \%$ FRBE-treated cells, $9.0 \pm 0.9 \mathrm{pg} / \mathrm{mL}$ in the $0.5 \%$ FRBE-treated cells, and $8.9 \pm 0.2 \mathrm{pg} / \mathrm{mL}$ in the $1.0 \%$ FRBE-treated cells. FRBE treatment reduced the UV-Binduced release of IL- $1 \alpha$, which appeared to recover to values found in non-irradiated controls (Fig. 5).

To determine whether FRBE inhibited the expression of MMP-1 induced by UV-B, fibroblasts were irradiated with UV-B $\left(30 \mathrm{~mJ} / \mathrm{cm}^{2}\right)$ and incubated with or without FRBE. Pro-MMP-1 increased approximately fourfold in cells irradiated by UV-B without FRBE treatment as compared to non-irradiated cells. However, cells irradiated by UV-B and treated with FRBE experienced a decrease in proMMP-1 (Fig. 6a). In addition, western blot analysis found a decrease of MMP-1 expression in FRBE-treated cells (Fig. 6b).
Fig. 4 Immunohistochemical staining of pro-collagen in skin fibroblasts culture (a No UVirradiation, b UV-irradiation, c As-2p treatment after UVirradiation, d $0.1 \%$ FRBE treatment after UV-irradiation, $\mathbf{e}$ $0.5 \%$ FRBE treatment after UVirradiation, $\mathbf{f} 1 \%$ FRBE treatment after UV-irradiation). Original magnification: 100 , scale bar $200 \mu \mathrm{m}$
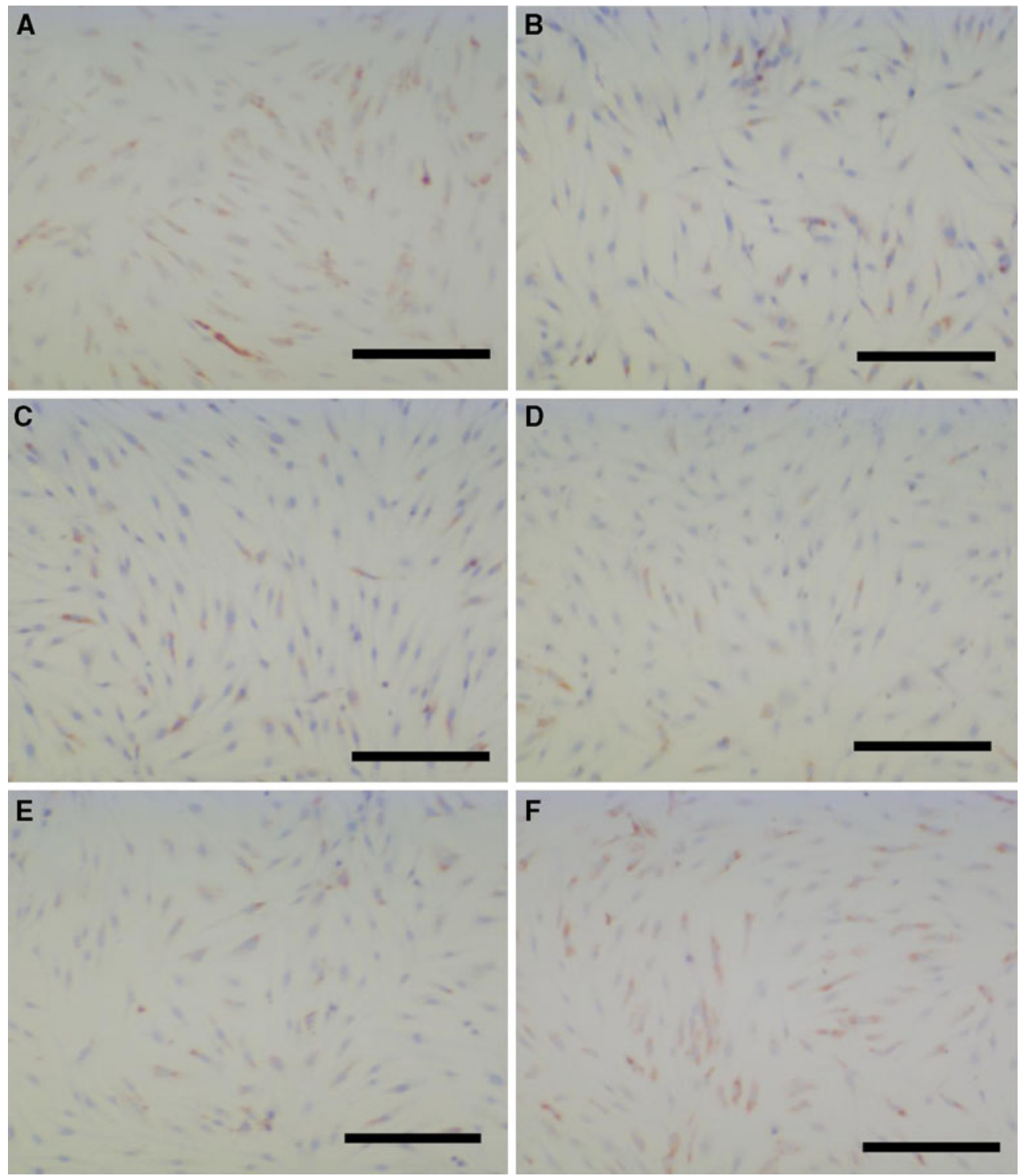


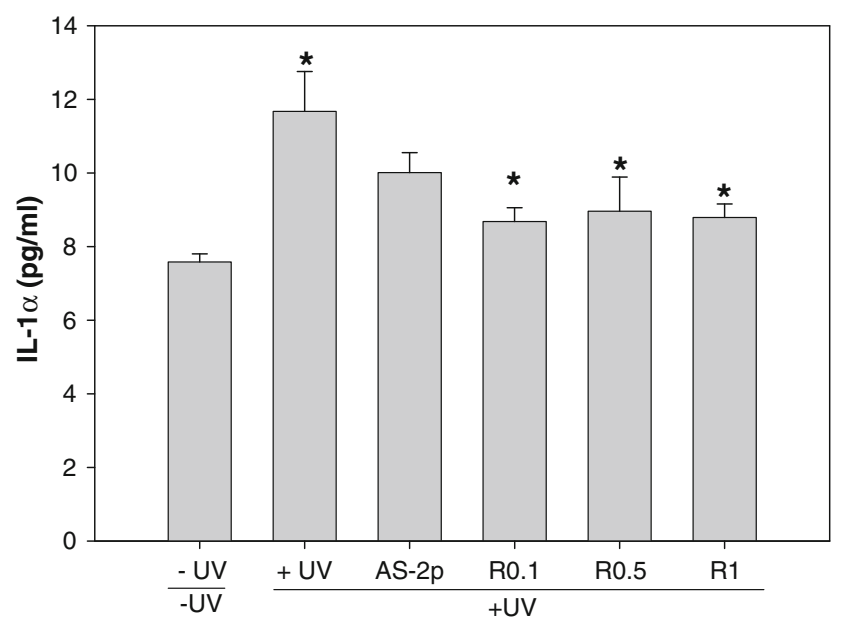

Fig. 5 Effect of FRBE on the secretion of IL- $1 \alpha$ in skin fibroblasts exposed to UV-B radiation at $30 \mathrm{~mJ} / \mathrm{cm}^{2}(n=6)$. Data are expressed as mean $\pm \mathrm{SD}$ of six samples $\left({ }^{*} P<0.05\right)$

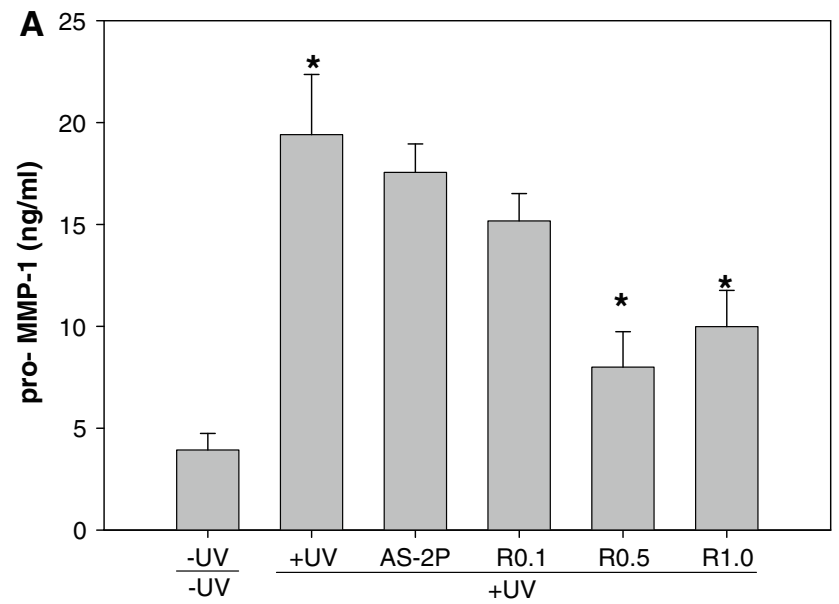

B

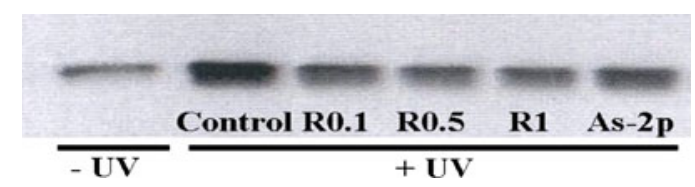

Fig. 6 Effect of FRBE on a the secretion of pro-MMP-1 $(n=6)$, and b the expression of MMP-1 in fibroblasts exposed to UV-B radiation at $30 \mathrm{~mJ} / \mathrm{cm}^{2}$. Data are expressed as mean $\pm \mathrm{SD}$ of six samples $(* P<0.05)$

Some investigators suggest that ERK serves as an antiinflammatory signal that suppresses expression of NF-kBdependent inflammatory genes by inhibiting IKK (IkB kinase) activity in cells [26]. In our previous study, the effect of the FRBE on ERK activation was analyzed by measuring the phosphorylated form of ERK ( $p$-ERK). The level of $p$-ERK (the activated form) increased until $60 \mathrm{~min}$ after treatment, and it gradually returned to the base level [25]. Therefore, we hypothesized that the ERK pathway is related to a decrease of IL- $1 \alpha$ and MMP-1 expression.
In this study, we found that FRBE can increase the synthesis of pro-collagen while inhibiting the synthesis of MMP-1 in cultured dermal fibroblasts. In addition, we found that FRBE can reduce UV-induced inflammation by decreasing IL- $1 \alpha$, a known inducer of MMP-1 production.

Previous papers have demonstrated the effects of Jacquez grape wine extract (JW-E) on the UV-induced release of inflammation mediators using a 3D epidermal skin model. Pre-treatment with JW-E reduced the UV-induced release of IL- $1 \alpha$ and $\mathrm{PGE}_{2}$ to values found in non-irradiated controls [27]. We postulated that the effects of FRBE may be due to its anti-oxidant activity. Rice bran contains various lipids, proteins, vitamin $\mathrm{B}$, essential amino acids, tocopherols, tocotrienols, and polyphenolic compounds (e.g. ferulic acid, p-coumaric acid) [11, 28, 29]. Exposure to UV radiation generates reactive oxygen/nitrogen species resulting in oxidative damage to tissue. These events can lead to diseases related to UV-radiation, such as irritation or sunburn, photoallergy, immunosuppression, and photoaging. Ferulic acid affects stable phenoxyl radical formation and thereby potentiates its ability to terminate free radical chain reaction [9]. Indeed, Ferulic acid may be an important antioxidant that preserves the physiological integrity of cells exposed to both air and increased UV radiation. Compared to untreated controls, ferulic acid exhibited a greater than $60 \%$ inhibition of UV-induced oxidation in erythrocytes and low-density lipoprotein (LDL) while maintaining normal glutathione levels and peroxidase activity in hemolysate from erythrocytes exposed to UV radiation [30]. Ferulic acid can further reduce the production of macrophage inflammatory protein-2 (MIP-2) and TNF- $\alpha$ in a mouse macrophage cell line stimulated by lipopolysaccharide (LPS) [31]. Moreover, Ferulic acid significantly inhibited the release of proinflammatory factors such as NO or TNF- $\alpha$, and it inhibited the proliferation of spleen cells induced by mitogens such as phytohemagglutinin (PHA) and concanavalin A (Con A) [32].

Anthocyanins and cyanidin, extracted from tart cherries, also have proven anti-inflammatory properties; they reduce the activities of prostaglandin endoperoxide $\mathrm{H}$ synthease-1 and -2 (PGHS-1, PGHS-2). The PGHS-1 and PGHS-2 enzymes can convert arachidonic acid to PGs [33]. Cyclooxygenase (COX) is an important enzyme in the biosynthesis of pro-inflammatory prostaglandins (PGs), and ferulic acid derivatives decreased COX-2 promoter activity [34] and simultaneously inhibited the release of TNF- $\alpha$ [35]. We believe that such a mechanism may be related effect of FRBE.

This study demonstrates that FRBE has potential as an anti-aging agent by stimulating collagen synthesis, decreasing IL- $1 \alpha$ levels, and decreasing MMP- 1 expression in skin fibroblasts. Furthermore, we suggest that the anti- 
aging activities of FRBE might be the result of an ERK signaling pathway, as observed in our previous study. Based on these observations, further animal studies are necessary to determine if FRBE can prevent photoaging.

Open Access This article is distributed under the terms of the Creative Commons Attribution Noncommercial License which permits any noncommercial use, distribution, and reproduction in any medium, provided the original author(s) and source are credited.

\section{References}

1. Bosset S, Bonnet-Duquennoy M, Barre P, Chalon A, Kurfurst R, Bonte F, Chnebert S, Le Varlet B, Nicolas JF (2003) Br J Dermatol 149:826-835

2. Fisher GJ, Wang ZQ, Datta SC, Varani J, Kang S, Voorhees JJ (1997) N Engl J Med 337:1419-1428

3. F'guyer S, Afaq F, Mukhtar H (2003) Photodermatol Photoimmunol Photomed 19:56-72

4. Harborne JB, Williams CA (2000) Phytochemistry 55:481-504

5. Kim S, Kim Y, Kim JE, Cho KH, Chung JH (2008) Phytomedicine 15:340-347

6. Kim S, Chung JH (2008) Phytomedicine 15:749-753

7. Huang MT, Liu Y, Ramji D, Lo CY, Ghai G, Dushenkov S, Ho CT (2006) Mol Nutr Food Res 50:115-122

8. Nijveldt RJ, van Nood E, van Hoorn DE, Boelens PG, van Norren K, van Leeuwen PA (2001) Am J Clin Nutr 74:418-425

9. Srinivasan M, Sudheer AR, Menon VP (2007) J Clin Biochem Nutr 40:92-100

10. Saija A, Tomaino A, Trombetta D, Pasquale AD, Uccella N, Barbuzzi T, Paolino D, Bonina F (2000) Int J Pharm 199:39-47

11. Kim KM, Yu KW, Kang DH, Suh HJ (2002) Phytother Res $16: 700-702$

12. Akita T, Kuwahara A (1987) Kochi Joshi Daigaku Kiyo Shizen Kagakuhen 35:45-58

13. Juliano BO (1985) Rice bran. In: Juliano Bo (ed) Rice chemistry and technology. American Association of Cereal Chemists Inc, St Paul, pp 647-687

14. Miyazawa M, Oshima T, Koshio K, Itsuzaki Y, Anzai J (2003) J Agric Food Chem 51:6953-6956

15. Akihisa T, Yasukawa K, Yamaura M, Ukiya M, Kimura Y, Shimizu N, Arai K (2000) J Agric Food Chem 48:2313-2319
16. Hu C, Zawistowski J, Ling W, Kitts DD (2003) J Agric Food Chem 51:5271-5277

17. Choi SW, Nam SH, Choi HC (1996) Foods Biotechnol 5:305-309

18. Ichikawa H, Ichiyanagi T, Xu B, Yoshii Y, Nakajima M, Konishi T (2001) J Med Food 4:211-218

19. Yoon HH, Paik YS, Kim JB, Hahn TR (1995) Agric Chem Biotechnol 38:581-583

20. Tsuda T, Watanabe M, Ohshima K, Norinobu S, Sang WC, Kawakishi S, Osawa T (1994) J Agric Food Chem 42:2407-2410

21. Chung HS, Woo WS (2001) J Nat Prod 64:1579-1580

22. Hyun JW, Chung HS (2004) J Agric Food Chem 52:2213-2217

23. Nam SH, Choi SP, Kang MY, Kozukue N, Friedman M (2005) J Agric Food Chem 53:816-822

24. Hirotsune M, Haratake A, Komiya A, Sugita J, Tachihara T, Komai T, Hizume K, Ozeki K, Ikemoto T (2005) J Agric Food Chem 53:948-952

25. Chung SY, Seo YK, Park JM, Seo MJ, Park JK, Kim JW, Park CS (2009) Biosci Biotechnol Biochem 73:1704-1710

26. Maeng YS, Min JK, Kim JH, Yamagishi A, Mochizuki N, Kwon JY, Park YW, Kim YM, Kwon YG (2006) Cell Signal 18:9941005

27. Tomaino A, Cristani M, Cimino F, Speciale A, Trombetta D, Bonina F, Saija A (2006) Toxicol In Vitro 20:1395-1402

28. Higashi-Okai K, Kanbara K, Amano K, Hagiwara A, Sugita C, Matsumoto N, Okai Y (2004) Phytother Res 18:628-633

29. Tian S, Nakamura K, Kayahara H (2004) J Agric Food Chem 52:4808-4813

30. Hsieh CL, Yen GC, Chen HY (2005) J Agric Food Chem 53:6151-6155

31. Sakai S, Ochiai H, Nakajima K, Terasawa K (1997) Cytokine 9:242-248

32. Ou L, Kong LY, Zhang XM, Niwa M (2003) Biol Pharm Bull 26:1511-1516

33. Wang H, Nair MG, Strasburg GM, Chang YC, Booren AM, Gray JI, DeWitt DL (1999) J Nat Prod 62:294-296

34. Hosoda A, Ozaki Y, Kashiwada A, Mutoh M, Wakabayashi K, Mizuno K, Nomura E, Taniguchi H (2002) Bioorg Med Chem 10:1189-1196

35. Murakami A, Nakamura Y, Koshimizu K, Takahashi D, Matsumoto K, Hagihara K, Taniguchi H, Nomura E, Hosoda A, Tsuno T, Maruta Y, Kim HW, Kawabata K, Ohigashi H (2002) Cancer Lett 180:121-129 